\title{
Rethinking Coordination in Large-Scale Software Development
}

\author{
Torgeir Dingsøyr \\ SINTEF Digital \\ 7465 Trondheim \\ Norway \\ torgeird@sintef.no
}

\author{
Finn Olav Bjørnson \\ Department of Computer Science \\ Norwegian University of Science and \\ Technology \\ bjornson@idi.ntnu.no
}

\author{
Nils Brede Moe \\ SINTEF Digital \\ 7465 Trondheim \\ Norway \\ nils.b.moe@sintef.no
}

\author{
Knut Rolland \\ SINTEF Digital \\ 7465 Trondheim \\ Norway \\ knut.rolland@sitnef.no
}

\author{
Eva Amdahl Seim \\ SINTEF Technology and Society \\ 7465 Trondheim \\ Norway \\ eva.a.seim@sintef.no
}

\begin{abstract}
Coordination was early identified as a key challenge in software development, and in particular in large development projects. With the arrival of agile methods and their increasing use also in large-scale projects, this calls for rethinking how the software engineering community addresses coordination. We argue for increasing the focus on coordination in software engineering and describe four directions for research. Focus on these areas can supplement advice given in current development methods with relevant research-based advice.
\end{abstract}

\section{CCS CONCEPTS}

- Software and its engineering $\rightarrow$ Software creation and management; Software development process management;

\section{KEYWORDS}

Coordination, large-scale agile development

\section{INTRODUCTION}

Large software projects were early identified as a challenge in software engineering, where Curtis et al. [1], found that "the thin spread of application domain knowledge, fluctuating and conflicting requirements, and communication bottlenecks and breakdownsaffected software productivity and quality".

Permission to make digital or hard copies of part or all of this work for personal or classroom use is granted without fee provided that copies are not made or distributed for profit or commercial advantage and that copies bear this notice and the full citation on the first page. Copyrights for third-party components of this work must be honored. For all other uses, contact the Owner/Author. CHASE'18, May 27, 2018, Gothenburg, Sweden $\odot 2018$ Copyright is held by the owner/author(s). ACM ISBN 978-1-4503-5725-8/18/05.

https://doi.org/10.1145/3195836.3195850
A more recent study of large-scale projects and coordination breakdowns state that "the success of software development projects depends on carefully coordinating the effort of many individuals across the multiple stages of the development process" [2]. A survey on coordination in large-scale software teams found respondents to hope for more effective and efficient communication and an emphasis on the importance of good personal relationships [3].

Coordination is important in software development, and in large-scale projects this is even more important as the number of developers and other stakeholders increase, and as the size of the technical system increases.

Coordination is often defined as "management of interdependencies between activities" [4] and coordination mechanisms as "the organizational arrangements that allow individuals to realize a collective performance" [5]. Mechanisms for coordination include direct supervision, mutual adjustment, and standardization of work, outputs, skills, and norms [6]. Some of these have been studied in computer-supported cooperative work.

Software development today is primarily conducted using agile methods [7]. These methods "de-emphasize traditional coordination mechanisms such as forward planning, extensive documentation, specific coordination roles, contracts, and strict adherence to a pre-defined specified process" [8]. When agile methods are applied to large-scale projects, new coordination challenges arise. In a study challenging underlying assumptions in large-scale agile development, Rolland et al. [9] found that current studies of agile methods share several assumptions that are challenged when a development project is conducted by a large number of teams. In this setting, work across teams becomes at least as important as work within teams.

New challenges are exemplified in a study of a coordination breakdown in a large-scale agile project, reported by Paasivaara and Lassenius [10]. They found that teams who followed the agile practice of coordinating through Scrum of Scrums were not able 
to coordinate effectively. Bick et al. [11] identified a lack of dependency awareness across teams as a primary cause of ineffective coordination. This lack of awareness stemmed from misaligned planning activities. An exploratory study of a largescale agile development programme identified several more coordination arenas than prescribed in agile methods, and also found that these arenas change over time [12].

\section{APPROACHES TO COORDINATION}

Four approaches to coordination are used in studies [8, 13-15] which address challenges with large-scale agile development:

In Software Engineering, Strode et al [8] have suggested a coordination model based on a study of co-located agile development teams. A coordination strategy consisting of three components: Synchronization such as a daily meeting where all team members meet at the same time and place. Structure, which includes physical closeness, team member availability and that team members can substitute others, and finally: Boundary spanning, which includes activities, artefacts and roles to coordinate with other people or units beyond the project. Developed from studies of agile teams, this model puts particular emphasis on coordination with a team, and coordination using oral communication and physical artefacts.

In Sociology, van de Ven et al. [16] discussed three main determinants for how organizations coordinate. Coordination is seen as either done through persons ("personal") or through artefacts ("impersonal"). If coordination is done through persons, it could be done individually or in groups. Impersonal coordination is "programmed" or "codified" for example through plans or written coding standards. The study shows that when task uncertainty, task interdependence and size of work unit change, the coordination mechanism also changes. This emphasis on uncertainty, dependencies and size is relevant for large-scale development projects where dependencies have been identified as a main challenge, task uncertainty has long been recognized as a challenge in software development, and a large-scale development project per definition will involve a high number of people.

Organizational Psychology has recently studied multiple teams that work to achieve a common goal, multiteam systems [14]. Mechanisms for coordination on team level are seen as relevant for inter-team coordination. The big five model [17] describe three coordination mechanisms: Shared mental m,odels, a common understanding of tasks, work process and knowledge of others. Closed-loop communication, that senders of messages ensures that the message is correctly received. Mutual trust, a shared belief that team members will perform roles and protect interests of teammates. These mechanisms put emphasis on the importance of relations between individuals for coordination.

Moreover, in Management Science researchers refer to the process of Coordinating to underscore the dynamic and emergent characteristics of coordination mechanisms. Jarzabkowski et al. [18] argue that coordinating mechanisms are subject for change, are established, fall apart, and are transformed over time. This lens on coordinating mechanisms can be helpful for understanding how mechanisms need to change over time in large projects.

\section{CONCLUSIONS}

Software engineering can draw on number of relevant studies and theories in order to provide research-based advice on coordination. The complexity of large-scale agile development calls for rethinking coordination, emphasizing characteristics such as: oral communication, work in teams, a high level of interdependencies, uncertainty in tasks, many people involved, relations between individuals and that coordination needs change over time. We hope this research note will inspire others to focus future studies on managing challenges with coordination.

\section{ACKNOWLEDGMENTS}

This work was supported by the Research council of Norway (grant 236759) and by companies Kantega, Kongsberg Defence \& Aerospace, Sopra Steria, Statoil and Sticos.

\section{REFERENCES}

[1] Curtis, B., Krasner, H., and Iscoe, N., "A field study of the software design process for large systems," Communications of the ACM, vol. 31, pp. 1268-1287, 1988.

[2] Cataldo, M. and Herbsleb, J. D., "Coordination Breakdowns and Their Impact on Development Productivity and Software Failures," IEEE Transactions on Software Engineering, vol. 39, pp. 343-360, 2013.

[3] Begel, A., Nagappan, N., Poile, C., and Layman, L., "Coordination in large-scale software teams," in Proceedings of the 2009 ICSE Workshop on Cooperative and Human Aspects on Software Engineering, 2009, pp. 1-7.

[4] Malone, T. W. and Crowston, K., "The interdisciplinary study of coordination," ACM Computing Surveys (CSUR), vol. 26, pp. 87-119, 1994.

[5] Okhuysen, G. A. and Bechky, B. A., "Coordination in organizations: An integrative perspective," The Academy of Management Annals, vol. 3, pp. 463$502,2009$.

[6] Mintzberg, H., Mintzberg on management: Inside our strange world of organizations: Simon and Schuster, 1989.

[7] Dingsøyr, T., Nerur, S., Balijepally, V., and Moe, N. B., "A Decade of Agile Methodologies: Towards Explaining Agile Software Development," Fournal of Systems and Software, vol. 85, pp. 1213-1221, 2012.

[8] Strode, D. E., Huff, S. L., Hope, B. G., and Link, S., "Coordination in co-located agile software development projects," Journal of Systems and Software, vol. 85, pp. 1222-1238, 2012.

[9] Rolland, K. H., Fitzgerald, B., Dingsøyr, T., and Stol, K.-J., "Problematizing Agile in the Large: Alternative Assumptions for Large-Scale Agile Development," in International Conference on Information Systems, Dublin, Ireland, 2016.

[10] Paasivaara, M., Lassenius, C., and Heikkila, V. T., "Inter-team Coordination in Large-Scale Globally Distributed Scrum: Do Scrum-of-Scrums Really Work?," in Proceedings of the ACM-IEEE International Symposium on Empirical Software Engineering and Measurement, ed New York: IEEE, 2012, pp. 235-238.

[11] Bick, S., Spohrer, K., Hoda, R., Scheerer, A., and Heinzl, A., "Coordination Challenges in Large-Scale Software Development: A Case Study of Planning Misalignment in Hybrid Settings," IEEE Trans. on Software Engineering, 2017.

[12] Dingsøyr, T., Moe, N. B., Fægri, T. E., and Seim, E. A., "Exploring Software Development at the Very Large-Scale: A Revelatory Case Study and Research Agenda for Agile Method Adaptation," Empirical Software Engineering, 2017.

[13] Dingsøyr, T., Moe, N. B., and Seim, E. A., "Coordinating Knowledge Work in Multi-Team Programs: Findings from a Large-Scale Agile Development Program," to appear in Project Management fournal, vol. https://arxiv.org/abs/1801.08764, 2018.

[14] Scheerer, A. and Kude, T., "Exploring Coordination in Large-Scale Agile Software Development: A Multiteam Systems Perspective," in Proceedings of the International Conference on Information Systems, ed, 2014.

[15] Bjørnson, F. O., Wijnmaalen, J., Stettina, C. J., and Dingsøyr, T., "Inter-team Coordination in Large-Scale Agile Development: A Case Study of Three Enabling Mechanisms," presented at the Submitted to XP2018, 2018.

[16] Van de Ven, A. H., Delbecq, A. L., and Koenig Jr, R., "Determinants of coordination modes within organizations," American sociological review, pp. 322-338, 1976.

[17] Salas, E., Sims, D. E., and Burke, S. C., "Is there a "Big five" in teamwork?," Small Group Research, vol. 36, pp. 555-599, 2005.

[18] Jarzabkowski, P. A., Le, J. K., and Feldman, M. S., "Toward a Theory of Coordinating: Creating Coordinating Mechanisms in Practice," Organization Science, vol. 23, pp. 907-927, Jul-Aug 2012. 